\title{
The Frequency of Circulating Tumour Cells and the Correlation with the Clinical Response to Standard Chemoradiotherapy in Locally Advanced Nasopharyngeal Carcinoma: A Prospective Study
}

This article was published in the following Dove Press journal:

Cancer Management and Research

\begin{abstract}
Yu Qian, ${ }^{1,2, *}$ Yuan Wu, ${ }^{3, *}$ Zilong Yuan, ${ }^{4}$ Xiaohui Niu, ${ }^{5}$ Yaoyao He, ${ }^{4}$ Jun Peng, ${ }^{6}$ Fuxiang Zhou, (D) ' Shaozhong Wei, ${ }^{7}$ Desheng $\mathrm{Hu}{ }^{3}$ Yunfeng Zhou (D)

'Department of Radiation and Medical Oncology, Zhongnan Hospital, Wuhan University, Wuhan, Hubei, People's Republic of China; ${ }^{2}$ Department of Medical Oncology, Hubei Cancer Hospital, Wuhan, Hubei, People's Republic of China; ${ }^{3}$ Department of Radiation Oncology, Hubei Cancer Hospital, Wuhan, Hubei, People's Republic of China; ${ }^{4}$ Department of Radiology, Hubei Cancer Hospital, Wuhan, Hubei, People's Republic of China; ${ }^{5}$ College of Informatics, Huazhong Agricultural University, Wuhan, Hubei, People's Republic of China; ${ }^{6}$ Department of Pathology, Hubei Cancer Hospital, Wuhan, Hubei, People's Republic of China;

${ }^{7}$ Department of Surgery, Hubei Cancer Hospital, Wuhan, Hubei, People's Republic of China
\end{abstract}

*These authors contributed equally to this work

Correspondence: Yunfeng Zhou Department of Radiation and Medical Oncology, Zhongnan Hospital, 169

Donghu Road, Wuhan, Hubei, People's

Republic of China

Tel +86 I39 07I5 4247

Fax +86 2767812892

Email yfzhouwhu@।63.com

Desheng $\mathrm{Hu}$

Department of Radiation Oncology,

Hubei Cancer Hospital, 16 Zhuodaoquan

S Road, Wuhan, Hubei, People's Republic of China

Tel +8627876703I8

Fax +862787670151

Email hds13907I74495@I63.com
Purpose: Circulating tumour cells (CTCs) have been found to correlate with treatment response and prognosis in some cancers; however, such correlations have not been reported in nasopharyngeal carcinoma (NPC). We aimed to determine the relationship between CTCs and the treatment response in NPC.

Patients and methods: In this prospective study, we ascertained the karyotype of CTCs and identified a possible correlation between karyotype and treatment response in locally advanced NPC (LANPC). We prospectively collected peripheral blood from LANPC patients. CTCs were measured by negative enrichment with immunofluorescence in situ hybridization (imFISH) and a centromere of chromosome 8 (CEP8) probe. Chromosome 8 was karyotyped in CTCs, which were identified as triploid, tetraploid or multiploid. Patients were then treated with platinum-based induction chemotherapy followed by concurrent chemoradiotherapy. CTCs were measured before and after treatment.

Results: We detected CTCs in 27 of 50 (54\%) patients, which served as a baseline value. The results were independent of age, smoking history and NPC clinical stage. All of the 27 evaluable enrolled patients with detectable CTCs showed decreases in both total CTCs and CTCs of different ploidies after treatment $(\mathrm{P}<0.05)$. Reductions in CTCs were significantly more common in patients with a complete response (CR) than in those with a partial response $(\mathrm{PR})(\mathrm{P}<0.05)$. The presence of fewer tetraploid CTCs before treatment had a positive predictive value for a $\mathrm{CR}$ to chemoradiotherapy $(\mathrm{P}<0.05)$. CTC-positive patients had a shorter PFS after treatment $(\mathrm{P}=0.03)$.

Conclusion: The decrease in CTCs was correlated with therapeutic efficacy in patients with LANPC, and the presence of tetraploid CTCs before treatment is a potential predictive factor for clinical outcomes.

Keywords: CTC, NPC, therapeutic efficacy, chemoradiotherapy

\section{Introduction}

Circulating tumour cells (CTCs) are cells that have been shed from a primary tumour into the vasculature or lymphatics, thought which they move around the body. ${ }^{1,2}$ Due to this feature, CTCs have been used as a biomarker in various cancers. The frequency of CTCs can be influenced by the stage at diagnosis, detection methods and surgical intervention. ${ }^{3}$ The presence of CTCs indicates a poor prognosis and predicts tumour progression in many cancers, such as breast, lung, prostate, oesophageal and colorectal cancers. ${ }^{3,4}$ 
Several studies have focused on the association of CTCs with tumour stage and their predictive role in prognosis and treatment response in head and neck cancer, but the results are controversial. ${ }^{5}$ Some studies showed that a high frequency of CTCs was associated with nodal stage, ${ }^{6}$ while others showed that CTCs could not predict the cancer burden in head and neck cancer. ${ }^{5}$ Moreover, several studies indicated that therapeutic interventions such as surgery and radiotherapy had some impact on the frequency of CTCs. ${ }^{7-9}$ Therefore, it is difficult to determine the roles and activities of CTCs in heterogeneous patient populations with various cancer diagnoses and different clinical interventions. We focused on CTCs in a patient population with the same stage of a specific type of head and neck cancer on the same therapeutic regimen.

Nasopharyngeal carcinoma (NPC) is a unique type of head and neck cancer that originates in the nasopharynx and has a high risk of metastasis, and it is mainly treated with radiotherapy with/without chemotherapy due to inoperability based on anatomic features. CTC studies in NPC are quite limited, and the results are controversial, as are those in other types of head and neck cancer. ${ }^{10-12}$ To prevent potential bias related to stage and therapeutic interventions, we designed a prospective study to determine the role of CTCs in patients with locally advanced NPC (LANPC) who underwent the same induction chemotherapy and concurrent chemoradiotherapy regimen. In this study, CTCs were detected before and after chemoradiotherapy in LANPC patients, and changes in CTCs and the clinical response after therapy were correlated. We further characterized the predictive value of clinical factors, including CTCs.

\section{Materials and Methods}

\section{Patients}

The study was approved by the local ethics committee at Hubei Cancer Hospital (2015 No. 6) and conducted in accordance with the Declaration of Helsinki. There were 189 patients screened at our Department of Head and Neck Cancer from August 2015 to September 2016. Eligible criteria included (a) age between 18 and 70 years and (b) a histological and imaging-confirmed diagnosis of LANPC. The histological type of NPC was WHO type III. The seventh edition of the UICC/AJCC tumour-node-metastasis classification (TNM) for NPC was applied to stage all the patients, and stage III to IVb disease was defined as LANPC. After providing written informed consent, 89 consecutive patients were enrolled in this study; 50 patients finished the entire treatment regimen and had a 3-year follow-up. None of the patients received any anti-tumour therapy before the first blood sampling. Eighty-seven patients had blood drawn for testing at different time intervals before and after treatment to evaluate the number of CTCs at diagnosis and after treatment. The last CTC analysis was conducted at the first follow-up (3 months after treatment). Patient data were collected from August 2015 to June 2019, and the followup period ranged from 25 to 41 months.

All patients underwent two cycles of induced chemotherapy with raltitrexed and cisplatin, ${ }^{13,14}$ followed by the same regimen concurrent with radiotherapy (two cycles of concurrent combination chemotherapy plus radical intensitymodulated radiation therapy). The regimen was raltitrexed $2.5 \mathrm{mg} / \mathrm{m}^{2}$, IV in $15 \mathrm{mins}$, d1 plus cisplatin, $25 \mathrm{mg} / \mathrm{m}^{2}$, IV, d13 , cycled every 21 days. The treatment response was evaluated with the same imaging techniques used for diagnosis (computed tomography [CT], magnetic resonance imaging [MRI], and ultrasound [US]). These evaluations were performed for all enrolled patients 3 months after the completion of concurrent treatment and up to a follow-up of 3 years. The response was classified according to Response Evaluation Criteria in Solid Tumours (RECIST 1.1) as follows. Complete response (CR): disappearance of all target lesions (tumour and lymph node lesions). Any pathological lymph nodes (whether target or non-target) must have a reduction in short axis to $<10 \mathrm{~mm}$. Partial response (PR): at least a $30 \%$ decrease in the sum of diameters of target lesions, taking as reference the baseline sum diameters. Progressive disease (PD): at least a $20 \%$ increase in the sum of diameters of target lesions, taking as reference the smallest sum on study (this includes the baseline sum if that is the smallest in the study). In addition to the relative increase of $20 \%$, the sum must also demonstrate an absolute increase of at least $5 \mathrm{~mm}$. (Note: the appearance of one or more new lesions is also considered progression). Stable disease (SD): neither sufficient shrinkage to qualify for PR nor sufficient increase to qualify for PD, taking as reference the smallest sum diameters while on study. ${ }^{15}$

\section{Isolation and Identification of CTCs}

We used a negative enrichment method for CTCs. Six millilitres of peripheral blood were collected, and after lysing red blood cells with lysing buffer (Cyttel, Jiangsu, China), the resulting cell pellet was incubated with anti-CD45 antibodyconjugated immuno-magnetic beads. White blood cells were separated by gradient centrifugation. Using a magnetic 
stand, the resulting solution containing CTCs was smeared on one slide, fixed and dried for subsequent analysis. The slide was used for immunofluorescence in situ hybridization (imFISH) with immunostaining of the white blood cell surface marker CD45, the nucleus marker 4',6-diamidino2-phenylindole (DAPI) and FISH with the centromere of chromosome 8 (CEP8) probe, according to the manufacturer's instructions (Cyttel, Jiangsu, China).

Cells were determined to be CTCs if they were negative for CD45, positive for DAPI and positive for more than two CEP8 signals (CD45-/DAPI+/CEP8 $\geq 3$ ). ${ }^{16,17}$ The karyotyping of cells that met these criteria allowed for the identification of triploid, tetraploid and multiploid CTCs.

\section{Statistical Analysis}

Data were analysed using the statistical analysis software SPSS 24.0. The association of CTC positivity (defined by $\geq 1$ CTC per $6 \mathrm{~mL}$ blood) with clinical parameters was assessed using Fisher's exact test or the chi-squared test. Spearman's rank-order correlation was used to analyse the relationship between CTC count and clinical outcomes. Logistic regression was applied to identify predictive factors for a complete response (CR) to anticancer therapy as the dependent variable. Correlations were considered statistically significant at $\mathrm{p}<0.05$. We defined progressionfree survival (PFS) and overall survival (OS) as the time from the date of diagnosis to the date of clinical disease progression, death, or the last follow-up. Log rank tests were used to detect significant differences between groups.

\section{Results \\ CTC Detection and Patients' Clinical Characteristics}

ImFISH identified CTC cells in peripheral blood as positive for DAPI, negative for the white blood cell marker CD45 and positive for more than two CEP8 signals. Figure 1A shows a typical CTC and white blood cells that are positive for CD45 and have two CEP8 signals. According to the number of CEP8 signals, CTCs were karyotyped as triploid (3), tetraploid (4) or multiploid (5+) (Figure 1B).

Among all the enrolled LANPC patients, 50 finished the entire treatment regimen and had evaluable clinical response by the 3 -year follow-up. The clinical characteristics of these patients are presented in Table 1 . The majority of the patients were male and aged 40-60 years. Ten patients $(20 \%)$ had a history of lymph node biopsy, and 16 patients had a positive family history of cancer. Most patients $(56 \%)$ were diagnosed with stage III disease. None of the collected demographic and clinical characteristics differed between patients with CTCs and those without CTCs. Before treatment, 27/50 patients (54\%) were positive for CTCs, and $25(50 \%), 13(23 \%)$ and 12 patients (24\%) were positive for triploid, tetraploid and multiploid CTCs, respectively. For CTC-positive patients, the baseline median

\section{A}
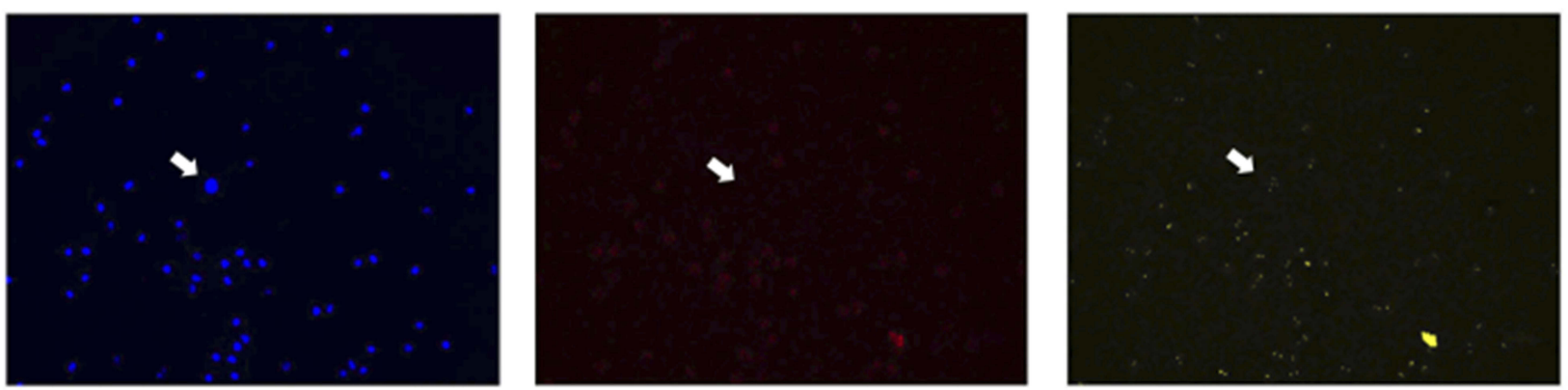

B
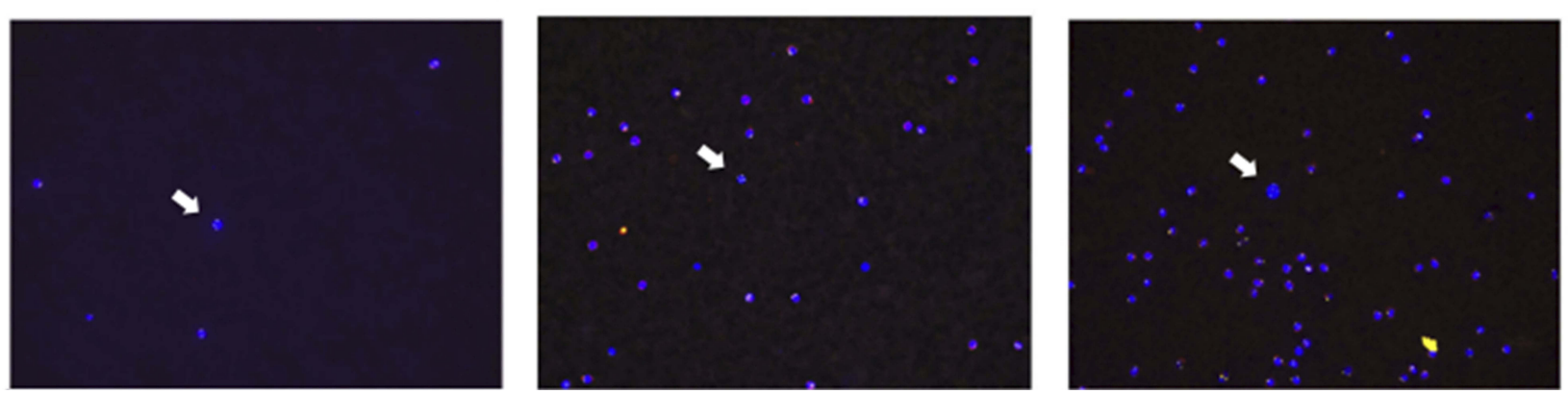

Figure I Typical CTCs and white blood cells. (A) imFISH identified DAPI-positive, CD45-negative CTCs with more than two CEP8 signals and DAPI-positive, CD45-positive white blood cells with two CEP8 signals. (B) CTCs according to the number of CEP8 signals: 3, triploid; 4, tetraploid; and 5 or more, multiploid. Arrows indicate CTCcells. 
Table I Demographic and Clinical Characteristics of Patients with and Without Circulating Tumor Cells

\begin{tabular}{|c|c|c|c|c|}
\hline & \multicolumn{3}{|c|}{ No. of Patients (\%) } & \multirow[t]{2}{*}{$\mathbf{P}$} \\
\hline & $\begin{array}{l}\text { Total } \\
\mathrm{N}=50\end{array}$ & $\begin{array}{l}\text { CTC- } \\
\text { Negative } \\
(\mathrm{N}=23)\end{array}$ & $\begin{array}{l}\text { CTC- } \\
\text { Positive } \\
(\mathbf{N}=27)\end{array}$ & \\
\hline \multicolumn{5}{|l|}{ Sex } \\
\hline Male & $30(60)$ & $13(57)$ & $17(63)$ & 0.64 \\
\hline Female & $20(40)$ & $10(43)$ & $10(37)$ & \\
\hline \multicolumn{5}{|l|}{ Age } \\
\hline$<40$ & $6(12)$ & $2(9)$ & $4(15)$ & 0.60 \\
\hline $40-60$ & $36(72)$ & $16(70)$ & $20(74)$ & \\
\hline$>60$ & $8(16)$ & $5(22)$ & $3(1 \mathrm{I})$ & \\
\hline \multicolumn{5}{|l|}{ Biopsy history } \\
\hline Positive & $10(20)$ & $5(22)$ & $5(19)$ & 1.0 \\
\hline \multicolumn{5}{|l|}{ Family history } \\
\hline $\begin{array}{l}\text { With positive } \\
\text { family history }\end{array}$ & $16(32)$ & $9(39)$ & $7(26)$ & 0.32 \\
\hline \multicolumn{5}{|l|}{$\begin{array}{l}\text { Smoking } \\
\text { status }\end{array}$} \\
\hline Positive $^{\mathrm{a}}$ & $25(50)$ & $12(52)$ & $13(48)$ & 0.77 \\
\hline \multicolumn{5}{|l|}{ Stage } \\
\hline III & $28(56)$ & $12(52)$ & $16(59)$ & 0.86 \\
\hline $\mathrm{IVa}$ & $15(30)$ & $8(35)$ & $7(26)$ & \\
\hline $\mathrm{IVb}$ & $7(14)$ & $3(13)$ & $4(15)$ & \\
\hline \multicolumn{5}{|l|}{ T stage } \\
\hline $\mathrm{T} 2$ & $6(12)$ & $2(9)$ & $4(15)$ & 0.66 \\
\hline T3 & $28(56)$ & $12(52)$ & $16(59)$ & \\
\hline T4 & $16(32)$ & 9 (39) & $7(26)$ & \\
\hline \multicolumn{5}{|l|}{ N stage } \\
\hline No-NI & II (22) & $6(26)$ & $5(19)$ & 0.66 \\
\hline N2 & $32(64)$ & $14(61)$ & $18(67)$ & \\
\hline N3 & $7(14)$ & $3(13)$ & $4(15)$ & \\
\hline
\end{tabular}

Note: ${ }^{a}$ Includes both former and current smokers.

CTC counts were 4 (range, 1-31) for total CTCs, 2 (range, 1-20) for triploid CTCs, 1 (range, 1-6) for tetraploid CTCs and 1.5 (range, 1-5) for multiploid CTCs.

\section{CTC Changes Correlated with the Treatment Response}

To determine whether the changes in CTCs correlate with the treatment response, we detected CTCs before and after treatment and analysed the results with the response evaluations. At 3 months after treatment, 30 patients $(60 \%)$ were determined to have CR, 12 (24\%) had PR and $4(8 \%)$ had SD. At the last follow-up, 3 years after treatment, 35
(70\%) patients had $\mathrm{CR}$ and $8(16 \%)$ had PD. Seven patients were lost to follow-up. The median number of total CTCs was dramatically decreased after chemoradiotherapy, from 4 to 0 , for patients with detectable CTCs at baseline $(\mathrm{P}<0.001)$. Only one patient harboured one CTC after chemoradiotherapy (Figure 2). For those patients with a CR to treatment, the numbers of triploid, tetraploid and multiploid CTCs were significantly decreased after treatment $(\mathrm{P}<0.05$, Table 2). For those patients who did not achieve a CR, the changes in karyotyped CTCs were not statistically significant (Table 2). Baseline analysis showed that all types of CTCs were less frequent in patients with a CR than in those who did not achieve a $\mathrm{CR}$, and the reduction was significant in only tetraploid CTCs $(\mathrm{P}=0.019)$.

To further elucidate factors predictive of the treatment response, univariate and multivariate analyses were used. The predictors of a CR to treatment are reported in Table 3. An older age (odds ratio $[\mathrm{OR}]=1.1 ; 95 \%$ confidence interval $[\mathrm{CI}]=1.0,1.2 ; \mathrm{P}=0.008)$ and fewer tetraploid CTCs $(\mathrm{OR}=0.5 ; 95 \% \mathrm{CI}=0.2,1.1 ; \mathrm{P}=0.045)$ were associated with a $\mathrm{CR}$ in patients with LANPC.

\section{Correlation of Baseline CTCs with Clinical Response During Follow-Up}

The chi-squared test showed no correlation between baseline CTC positivity before treatment and the clinical response at each indicated follow-up during a 3-year period (Table 4).

The correlation between CTCs and PFS and OS in LANPC patients is shown in Table 5. CTC-positive status was significantly correlated with a shorter PFS $(\mathrm{P}=0.03)$.

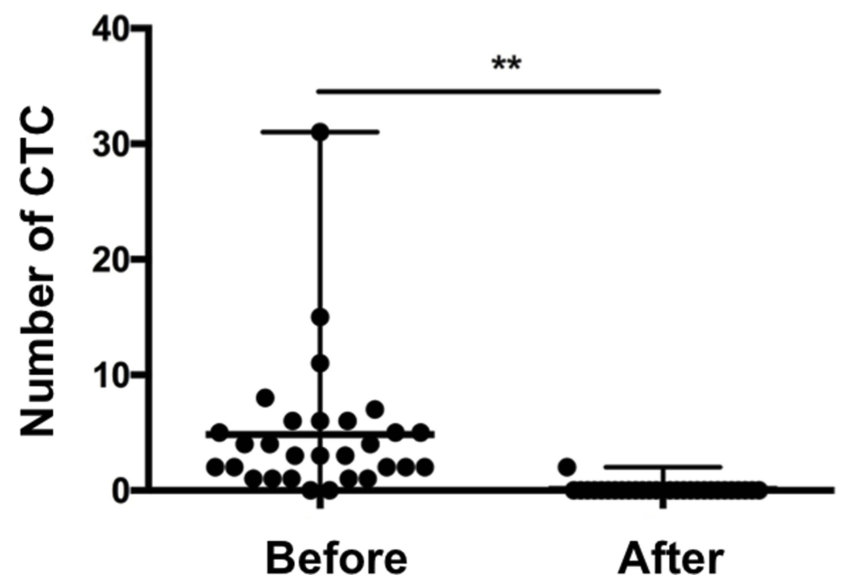

Figure 2 The change in total CTC count before and after treatment in baseline CTC-positive LANPC patients. ${ }^{*} \mathrm{P}<0.00 \mathrm{I}$. 
Table 2 CTC Changes Among Patients with and Without Complete Response to Treatment

\begin{tabular}{|c|c|c|c|}
\hline & \multicolumn{2}{|c|}{ No. of CTC (Mean \pm SD) } & \multirow[t]{2}{*}{$\mathbf{P}$} \\
\hline & $\begin{array}{l}\text { Before } \\
\text { Treatment }\end{array}$ & $\begin{array}{l}\text { After } \\
\text { Treatment }\end{array}$ & \\
\hline \multicolumn{4}{|l|}{ Patients with $C R$} \\
\hline Triploidy & $2.6 I \pm 2.25$ & $0.91 \pm 2.37$ & 0.017 \\
\hline Tetraploidy & $0.48 \pm 0.67^{\mathrm{a}}$ & $0.09 \pm 0.29$ & 0.015 \\
\hline Multiploidy & $0.61 \pm 0.89$ & 0 & 0.003 \\
\hline \multicolumn{4}{|l|}{ Patients without $C R$} \\
\hline Triploidy & $5.67 \pm 7.45$ & $0.5 \pm 0.84$ & 0.151 \\
\hline Tetraploidy & $2.00 \pm 2.27^{\mathrm{a}}$ & 0 & 0.136 \\
\hline Multiploidy & $1.67 \pm 1.97$ & $0.17 \pm 0.41$ & 0.122 \\
\hline
\end{tabular}

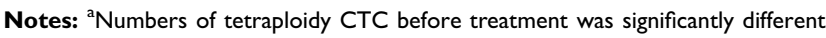
among patients with $C R$ and patients without $C R(P=0.019)$.

Abbreviations: CR, complete response; CTC, circulating tumor cell; NS, not significant; SD, standard deviation.

Table 3 Univariate and Multivariate Regression Analyses of Predictors for Complete Response to the Treatment in Patients with Locally Advanced Nasopharynx Carcinoma

\begin{tabular}{|c|c|c|c|c|}
\hline \multirow[t]{2}{*}{ Variable } & \multicolumn{2}{|c|}{ Univariate $^{\mathbf{a}}$} & \multicolumn{2}{|c|}{ Multivariate $^{b}$} \\
\hline & $\begin{array}{l}\text { OR } \\
(95 \% \mathrm{Cl})\end{array}$ & P-Value & $\begin{array}{l}\text { OR } \\
(95 \% \mathrm{Cl})\end{array}$ & P-Value \\
\hline Age & $\begin{array}{l}\text { I.I } \\
(I . I-I .2)\end{array}$ & 0.008 & $\begin{array}{l}\text { I.I } \\
(1.1-1.3)\end{array}$ & 0.005 \\
\hline Gender & $\begin{array}{l}2.6 \\
(0.8-8.3)\end{array}$ & 0.11 & & \\
\hline $\begin{array}{l}\text { Positive total } \\
\text { CTC }\end{array}$ & $\begin{array}{l}0.5 \\
(0.1-1.4)\end{array}$ & 0.17 & & \\
\hline Triploidy CTC & $\begin{array}{l}0.9 \\
(0.7-I . I)\end{array}$ & 0.31 & & \\
\hline $\begin{array}{l}\text { Tetraploidy } \\
\text { CTC }\end{array}$ & $\begin{array}{l}0.5 \\
(0.2-1.1)\end{array}$ & 0.045 & & \\
\hline $\begin{array}{l}\text { Multiploidy } \\
\text { CTC }\end{array}$ & $\begin{array}{l}0.5 \\
(0.2-1.2)\end{array}$ & 0.09 & & \\
\hline
\end{tabular}

Notes: anivariate logistic regression analysis was used to investigate variables as potential predictors of complete response to the treatment. Variables included, age, gender, TNM stage, positivity of circulating tumor cells; ${ }^{b}$ multivariate analysis was performed using the backward method.

Abbreviations: $\mathrm{Cl}$, confidence interval; $\mathrm{CTC}$, circulating tumor cells.

However, there were no differences in OS among patients with different baseline CTC statuses.

\section{Discussion}

Our study showed that CTCs were detected by the negative enrichment method in $54 \%$ of the patients with
Table 4 The Correlation Between the Number of Positive CTC Before Treatment and Clinical Response After Treatment and During Follow-Up

\begin{tabular}{|l|l|l|l|}
\hline \multirow{2}{*}{ Clinical Response } & \multicolumn{2}{|l|}{ No. of Patients } & \multirow{2}{*}{ P } \\
\cline { 2 - 3 } & CTC-Negative & CTC-Positive & \\
\hline $\begin{array}{l}\text { After treatment } \\
\text { CR }\end{array}$ & 13 & & \\
Non-CR & 10 & 10 & 0.17 \\
\hline $\begin{array}{l}\text { First follow-up } \\
\text { CR }\end{array}$ & 13 & 17 & \\
Non-CR & 10 & 17 & 0.64 \\
\hline Second follow-up & & 10 & \\
CR & 17 & 18 & \\
Non-CR & 6 & 9 & 0.58 \\
\hline
\end{tabular}

Notes: ${ }^{a}$ Three months after the treatment; ${ }^{\mathrm{b}}$ three years after the treatment. Abbreviations: $\mathrm{CR}$, complete response; $\mathrm{CTC}$, circulating tumor cell.

Table 5 Progression-Free and Overall Survival in LANPC Patients with Circulating Tumor Cells

\begin{tabular}{|c|c|c|c|c|}
\hline & $\begin{array}{l}\text { No. of } \\
\text { Patients }\end{array}$ & $\begin{array}{l}\text { No. of } \\
\text { Relapses } \\
\text { (\%) }\end{array}$ & $\begin{array}{l}\text { PFS Rate } \\
\text { at } 2 \text { Years } \\
(95 \% \mathrm{CI})\end{array}$ & $\begin{array}{l}\text { p Value } \\
\text { by log } \\
\text { rank } \\
\text { test }\end{array}$ \\
\hline CTC-positive & 27 & 7 (26\%) & $\begin{array}{l}75 \% \\
(0.6-0.9)\end{array}$ & 0.03 \\
\hline \multirow[t]{2}{*}{ CTC-negative } & 23 & I (4\%) & $\begin{array}{l}92 \% \\
(0.8-1.0)\end{array}$ & \\
\hline & $\begin{array}{l}\text { No. of } \\
\text { patients }\end{array}$ & $\begin{array}{l}\text { No. of } \\
\text { deaths } \\
\text { (\%) }\end{array}$ & $\begin{array}{l}\text { OS rate } \\
\text { at } 2 \text { years } \\
(95 \% \mathrm{Cl})\end{array}$ & \\
\hline CTC-positive & 27 & 3 (II\%) & $\begin{array}{l}91 \% \\
(0.8-1.0)\end{array}$ & 0.09 \\
\hline CTC-negative & 23 & $0(0)$ & $100 \%$ & \\
\hline
\end{tabular}

Abbreviations: $\mathrm{Cl}$, confidence interval; CTC, circulating tumor cells; No, number; PFS, progression-free survival; OS, overall survival.

LANPC. To date, this is the first study in NPC to show that changes in CTCs during chemotherapy and radiation therapy correlate with the treatment response. We also found that a fewer number of tetraploid CTCs and an older age before treatment were two predictive factors for achieving a $\mathrm{CR}$ to treatment.

The negative enrichment and imFISH methods have recently been tested and applied in patients with lung, bladder and gastric cancers, as well as NPC. ${ }^{18,19}$ The utility of this detection platform was confirmed in our 
study. Compared to the NPC study that showed diverse changes among patients with different responses, ${ }^{18,19}$ our study included only newly diagnosed patients; patients with disease relapse or distant metastasis were not included. Moreover, we monitored the variations in CTC count after chemotherapy and radiation therapy, which are currently the main therapeutic interventions for NPC. We found that after treatment, the number of CTCs significantly decreased in only patients with a CR. Although significant CTC changes might be due to a higher CTC count at baseline and/or a lower CTC count after treatment, CTC monitoring could be a complementary assessment for patients with a $\mathrm{CR}$ to confirm the clinical response to treatment.

CTCs in the bloodstream are thought to originate from the primary tumour, but the factors associated with the presence/absence of CTCs remain controversial in head and neck cancers. Some studies have shown that the presence of CTCs is associated with a high tumour burden, ${ }^{5,6,20}$ while others have not. ${ }^{21,22}$ Our study did not demonstrate that collected demographic or clinical factors were associated with CTC positivity in patients with LANPC. Similar studies on other potential factors could be performed. The regression analysis indicated that age was a predictive factor for $\mathrm{CR}$, confirming that elderly patients with LANPC might have a better clinical response. Consistently, patient age has been reported to be a significant independent prognostic factor in NPC. ${ }^{23}$

Several studies focused on the karyotypes of CTCs in different types of cancer but failed to demonstrate any promising findings. ${ }^{18,19}$ Our study first indicated the importance of tetraploid CTCs in predicting a CR to treatment; more research should be conducted to elucidate the potential underlying mechanism.

Although there is active research on the prognostic and predictive implications of CTCs in liquid biopsies in head and neck cancers, ${ }^{3,24}$ there is no convincing evidence supporting either the prognostic or predictive role of CTCs. Some studies have indicated a prognostic role of CTCs pertaining to disease progression in head and neck cancers. ${ }^{5,7}$ However, our study did not demonstrate the prognostic role of CTCs in LANPC within 3 years of follow-up. Among fifty enrolled patients, eight had relapsed by the last follow-up at 3 years. Longer followup should be performed to explore the role of CTCs in cancer patients who might have a comparable long disease-free survival.
Despite a rigorous study design, there were several limitations of this study. First, the data were from a single institution with a small number of patients with LANPC. Therefore, these findings cannot be generalized to all NPC patients. More studies with larger sample sizes are necessary in the future. Second, only eight patients in this study reported disease progression within the 3-year follow-up, making it impossible to statistically analyse the correlation of CTCs with prognosis. Third, CTCs were evaluated at only the first follow-up, and it would be difficult to constantly count CTCs during a 3-year followup. More research is necessary to provide more information in this area.

\section{Conclusion}

A CR to treatment correlated with a significant reduction in CTCs. Older age and fewer tetraploid CTCs before treatment were two predictive factors for a better response in LANPC.

\section{Acknowledgment}

We thank Prof. Qin Liu in the Department of Statistics at Wuhan University for assistance with the statistical analysis.

\section{Disclosure}

Yuan $\mathrm{Wu}$ is partially supported by the National Natural Science Foundation of China (Grant: 81401913). The authors report no other conflicts of interest in this work.

\section{References}

1. Pietras K, Ostman A. Hallmarks of cancer: interactions with the tumor stroma. Exp Cell Res. 2010;316(8):1324-1331. doi:10.1016/j.yexcr. 2010.02.045

2. Caceres G, Puskas JA, Magliocco AM. Circulating tumor cells: a window into tumor development and therapeutic effectiveness. Cancer Control. 2015;22(2):167-176. doi:10.1177/107327481502200207

3. Economopoulou P, Kotsantis I, Kyrodimos E, Lianidou ES, Psyrri A. Liquid biopsy: an emerging prognostic and predictive tool in Head and Neck Squamous Cell Carcinoma (HNSCC). Focus on Circulating Tumor Cells (CTCs). Oral Oncol. 2017;74:83-89.

4. Pantel K, Brakenhoff RH. Dissecting the metastatic cascade. Nat Rev Cancer. 2004;4(6):448-456. doi:10.1038/nrc1370

5. Hristozova T, Konschak R, Stromberger C, et al. The presence of circulating tumor cells (CTCs) correlates with lymph node metastasis in nonresectable squamous cell carcinoma of the head and neck region (SCCHN). Ann Oncol. 2011;22(8):1878-1885. doi:10.1093/annonc/mdr130

6. He S, Li P, He S, et al. Detection of circulating tumour cells with the CellSearch system in patients with advanced-stage head and neck cancer: preliminary results. J Laryngol Otol. 2013;127(8):788-793. doi:10.1017/S0022215113001412

7. Jatana KR, Balasubramanian P, Lang JC, et al. Significance of circulating tumor cells in patients with squamous cell carcinoma of the head and neck: initial results. Arch Otolaryngol Head Neck Surg. 2010;136 (12):1274-1279. doi:10.1001/archoto.2010.223 
8. Balasubramanian P, Lang JC, Jatana KR, et al. Multiparameter analysis, including EMT markers, on negatively enriched blood samples from patients with squamous cell carcinoma of the head and neck. PLoS One. 2012;7(7):e42048. doi:10.1371/journal.pone.0042048

9. Tinhofer I, Hristozova T, Stromberger C, Keilhoiz U, Budach V. Monitoring of circulating tumor cells and their expression of EGFR/phospho-EGFR during combined radiotherapy regimens in locally advanced squamous cell carcinoma of the head and neck. Int J Radiat Oncol Biol Phys. 2012;83(5):e685-e690. doi:10.1016/j. ijrobp.2012.02.009

10. Li F, Liu J, Song D, Zhang Q, Ding N, He X. Circulating tumor cells in the blood of poorly differentiated nasal squamous cell carcinoma patients: correlation with treatment response. Acta Otolaryngol. 2016;136(11):1164-1167. doi:10.1080/00016489.2016.1201861

11. Vo JH, Nei WL, Hu M, et al. Comparison of circulating tumour cells and circulating cell-free Epstein-Barr virus DNA in patients with nasopharyngeal carcinoma undergoing radiotherapy. Sci Rep. 2016;6(1):13. doi:10.1038/s41598-016-0006-3

12. Chen $\mathrm{Z}, \mathrm{Xu} \mathrm{L}, \mathrm{Xu} \mathrm{X}$, Yuan C. The clinical value of detecting circulating tumour cells in the peripheral blood of nasopharyngeal carcinoma patients. Oncol Lett. 2018;15(5):6283-6290. doi:10.3892/ ol.2018.8155

13. Planting A, de Jong M, Jansen P, Kerrebijn J, Smith M, Verweij J. Phase I study of concomitant chemoradiation with raltitrexed in locally advanced head and neck cancer. Eur J Cancer. 2015;41 (1):93-97. doi:10.1016/j.ejca.2004.09.022

14. Galetta D, Giotta F, Rosati G, et al. Carboplatin in combination with raltitrexed in recurrent and metastatic head and neck squamous cell carcinoma: a multicentre phase II study of the Gruppo Oncologico Dell'Italia Meridionale (G.O.I.M.). Anticancer Res. 2005;25 (6C):4445-4449.

15. Eisenhauer EA, Verweij J, Eisenhauer EA, Verweij J. 11 new response evaluation criteria in solid tumors: recist guideline version 1.1. Ejc Suppl. 2009;7(2):5. doi:10.1016/S1359-6349(09)70018-7
16. Sun B, Liu H, Wang S, Xiang J, Liu X. Prognostic impact of circulating tumor cells in patients with ampullary cancer. $J$ Cell Physiol. 2017;233:7.

17. Li J, Wang Z, Chong T, et al. Over-expression of a poor prognostic marker in prostate cancer: AQP5 promotes cells growth and local invasion. World J Surg Oncol. 2014;12(1):284. doi:10.1186/14777819-12-284

18. Zhang J, Shi H, Jiang T, Liu Z, Lin PP, Chen N. Circulating tumor cells with karyotyping as a novel biomarker for diagnosis and treatment of nasopharyngeal carcinoma. BMC Cancer. 2018;18(1):1133. doi:10.1186/s12885-018-5034-x

19. Lin PP. Integrated EpCAM-independent subtraction enrichment and iFISH strategies to detect and classify disseminated and circulating tumors cells. Clin Transl Med. 2015;4(1):38. doi:10.1186/s40169015-0081-2

20. Nichols AC, Lowes LE, Szeto CC, et al. Detection of circulating tumor cells in advanced head and neck cancer using the CellSearch system. Head Neck. 2012;34(10):1440-1444. doi:10.1002/hed.21941

21. Buglione M, Grisanti S, Almici C, et al. Circulating tumour cells in locally advanced head and neck cancer: preliminary report about their possible role in predicting response to non-surgical treatment and survival. Eur J Cancer. 2012;48(16):3019-3026. doi:10.1016/j.ejca.2012.05.007

22. Guney K, Yoldas B, Ozbilim G, Derin AT, Sarihan S, Balkan E. Detection of micrometastatic tumor cells in head and neck squamous cell carcinoma. A possible predictor of recurrences? Saudi Med J. 2007;28(2):216-220.

23. Heng DM, Wee J, Fong KW, et al. Prognostic factors in 677 patients in Singapore with nondisseminated nasopharyngeal carcinoma. Cancer. 1999;86(10):1912-1920. doi:10.1002/(SICI)1097-0142(19991115)86:10<1912::AID-CNCR6>3.0.CO;2-S

24. Colnot DR, Nieuwenhuis EJ, Kuik DJ, et al. Clinical significance of micrometastatic cells detected by E48 (Ly-6D) reverse transcriptionpolymerase chain reaction in bone marrow of head and neck cancer patients. Clin Cancer Res. 2004;10(23):7827-7833. doi:10.1158/10780432.CCR-04-1090

\section{Publish your work in this journal}

Cancer Management and Research is an international, peer-reviewed open access journal focusing on cancer research and the optimal use of preventative and integrated treatment interventions to achieve improved outcomes, enhanced survival and quality of life for the cancer patient.
The manuscript management system is completely online and includes a very quick and fair peer-review system, which is all easy to use. Visit http://www.dovepress.com/testimonials.php to read real quotes from published authors. 